\title{
Stability Indicating HPLC Method using Core Shell Stationary Phase for the Determination of Related Substances in Levocetirizine Dihydrochloride Oral Solution
}

\author{
Venkatakrishna Akula ${ }^{\star 1,2,3}$, Barij Nayan Sinha1, Han Jeong Seok \\ ${ }^{1}$ Birla Institute of Technology, Mesra, Ranchi, Jharkhand, INDIA. \\ ${ }^{2} \mathrm{CJ}$ Pharma Research India Pvt. Ltd, Hyderabad, Telangana, INDIA. \\ ${ }^{3}$ Hetero Labs Ltd., Hyderabad, Telangana, INDIA.
}

\begin{abstract}
Introduction: Levocetirizine (LCZ) is a new generation antihistamine drug used for the allergic symptoms resulting from various diseases. The present research work focuses on the development of a simple and precise HPLC method for the effective separation and quantitative determination of LCZ and its impurities. Objectives: Eight potential related impurities of LCZ were separated and identified in the bulk drug as well as oral solution dosage form. Results: The separation was achieved on a core shell stationary phase Kinetex bipheyl $(250,4.6 \times 5 \mu \mathrm{m})$ column with mobile phase of sodium perchlorate in water and acetonitrile in a gradient elution. The results were monitored and analytes were quantified at $230 \mathrm{~nm}$. Conclusion: The proposed method was stability indicating and was validated as per ICH guidelines for specificity, linearity, precision, accuracy and robustness. The proposed method finds its application in the routine analysis of LCZ in bulk drug and various dosage forms.
\end{abstract}

Key words: HPLC, Core shell, Related Substances, Levocetirizine dihydrochloride.

\section{INTRODUCTION}

Levocetirizine (LCZ) is a third generation piperizine derivative indicated to be used as an effective antihistaminic (H1 blocker). ${ }^{1}$ LCZ is the active enantiomer of cetirizine. It is commonly prescribed to relieve from allergic symptoms like watery eyes, running nose, sneezing, hives, and itching. LCZ is commonly taken as an oral pill..$^{2-6}$ The purity of the pharmaceuticals is of utmost concern and the presence of various impurities in the bulk drug and finished pharmaceuticals greatly affect the compliance of the product. ${ }^{7}$ Thus it becomes important to provide good and efficient analytical methods which would be able to determine the analyte of interest in a simple, precise and accurate manner. The use of core shell technology stationary phases in the arena of separation science is certainly gaining more importance due to its good chromatographic properties like good peak shape and retention properties. $^{8-10}$ The lifetime of these columns are better when compared to that of conventionally used reverse phase columns. Thus developing analytical methods which involve using the core shell columns provides definitive advantages over traditionally used columns in terms of reproducibility and repeatability of the study. ${ }^{11-13}$

The literature showed various analytical methods reported for the determination of Levocetirizine using HPLC in bulk and dosage forms, in plasma and other biological matrices. Almost all the reported methods indicated the usage of conventional stationary phases. ${ }^{14-19}$ This motivated the authors to
Submission Date: 29-03-2017; Revision Date: 13-07-2017; Accepted Date: 17-05-2018

DOI: 10.5530/ijper.52.4.79 Correspondence: Venkatakrishna Akula, Analytical R\&D, Plot No 22-110, Hetero Labs Ltd., Hyderabad 500055, Telangana, INDIA.

Phone: +91-8977776007 E-mail:venkatakrishna45@ gmail.com

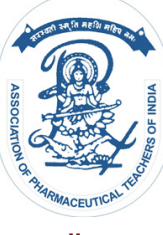

www.ijper.org 
develop simple, precise, accurate and robust HPLC method using the core shell technology stationary phase for the determination of LCZ in bulk and formulations.

\section{EXPERIMENTAL}

\section{Materials}

LCZ was obtained as a gratis sample from Hetero Labs Pvt. Ltd., Hyderabad. HPLC grade acetonitrile and ammonium acetate were purchased from Merck (Darmstadt, Germany). AR grade glacial acetic acid was procured from SD Fine-Chem. Ltd. (Mumbai, India). High purity water was obtained from Millipore Milli - Q plus system (Milford, MA, USA). Water and acetonitrile $(50: 50 \mathrm{v} / \mathrm{v})$ was used as the diluent and all the final solutions were made in the diluent.

\section{Instrumentation}

The liquid chromatographic analysis was performed on an Waters 2695 series HPLC (Waters Corporation) equipped with quaternary solvent manager, a degasser, an ultraviolet detector, an auto sampler and a column compartment with temperature regulation facility. The data acquisition was carried out using the Empower software (version 3)

\section{Chromatographic conditions}

The chromatographic separations were carried out on Kinetex bipheyl (250mm x $4.6 \mathrm{~mm}$ x $5 \mu \mathrm{m})$. The mobile phase composed of buffer solution $(6.0 \mathrm{gm}$ of sodium perchlorate monohydrate in $1000 \mathrm{~mL}$ water along with $2 \mathrm{~mL}$ of perchloric acid) of $\mathrm{pH} 2.0$ and acetonitrile in gradient elution. The gradient program set to achieve the separation was $0 / 20,70 / 25,80 / 30,90 / 30,100 / 40$, $110 / 40,115 / 70,125 / 70,130 / 20,140 / 20$. The flow rate

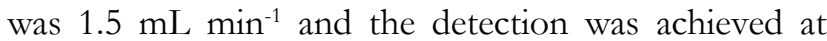
$230 \mathrm{~nm}$. The injection volume was $50 \mu \mathrm{L}$ with column oven maintained at $45^{\circ} \mathrm{C}$.

\section{Preparation of LCZ standard solution}

The drug substance LCZ was accurately weighed $(40 \mathrm{mg})$ and transferred into a $100 \mathrm{~mL}$ flask. About $60 \mathrm{~mL}$ of diluent was added and sonicated to dissolve the drug, then made up to the volume with diluent. $5 \mathrm{~mL}$ of the above solution was diluted to $100 \mathrm{~mL}$ with diluent to result the secondary stock solution. From the secondary stock solution a working standard solution was prepared $(1: 40 \mathrm{v} / \mathrm{v})$ with the diluent. The stock solution and also the working standards were stored at $10^{\circ} \mathrm{C}$ and were found to be stable for several days.

\section{Preparation of Sample}

The oral solution of LCZ equivalent to $10 \mathrm{mg}$ of LCZ was weighed into $100 \mathrm{~mL}$ flask; $40 \mathrm{~mL}$ diluent was added to dissolve the contents and final volume made up with the diluent to $100 \mathrm{~mL}$. The solution was sonicated for $30 \mathrm{~min}$ with intermediate shaking and then the was filtered through $0.45 \mu \mathrm{m}$ membrane filter.

\section{Method Validation}

The developed analytical method was validated according to the ICH Q2 (R1) guidelines. ${ }^{20}$ The various parameters which were evaluated under the validation process

\section{Precision}

The precision of an analytical procedure indicates the closeness of agreement between a set of measurements obtained from multiple sampling of the same sample under the prescribed conditions. For system precision and method precision standard solution and sample solutions (unspiked and spiked) were prepared as per test method and injected into the chromatographic system respectively.

\section{Accuracy}

It shows the closeness of the true value which is accepted or standard and the value which is obtained after the experimentation. In accuracy study, LCZ and its impurities were spiked to the placebo and sample solutions respectively at a concentration ranging from LOQ to $150 \%$. All the samples were injected in triplicate at each level.

\section{Linearity and range}

The linearity of an analytical method is the ability of the method to respond in direct proportion to that of concentration. The specific concentration levels within which the method shows a direct relation between the response and concentration is known as the linearity. The linearity was established from LOQ to $150 \%$ of the specification level of LCZ and the impurities.

\section{Robustness}

It shows the ruggedness of the method when deliberate but small changes are made to the parameters of the analytical method. This parameter builds in confidence into the method indicating the extent to which the method is capable of sustaining small variations while transfer of the method. To demonstrate the robustness of the proposed method in the present study, deliberate changes in the flow rate and column temperature were made. The observations were made by evaluating the 
system suitability parameters of the standard and \% RSD for the sample solutions.

\section{Limit of detection (LOD) and limit of quantification (LOQ)}

The determination of limit of detection and quantification of the drug and its impurities indicate the sensitivity of the method. It provides an estimate about the minimum levels from where the analytes can be invariably determined using the analytical method. LOD is the concentration where the signal to noise ratio is $3: 1$ and for LOQ it is 10:1.

\section{RESULTS AND DISCUSSION Optimization of HPLC conditions}

The development of a HPLC method for the determination of LCZ and its related substances was aimed at proposing a stability indicating method that can quantify LCZ in the presence of its excipients with good precision and accuracy (Figure 1). The first step was to find an appropriate wavelength where LCZ and all its impurities can be effectively determined without any compromise (which is commonly observed for compounds with different absorption maximum). A suitable wavelength was found experimentally after measuring spectra of the components to be separated and subsequently testing the detector response of analytes at $230 \mathrm{~nm}$. LCZ and its related substances showed different affinities and thereby various retentions for chromatographic stationary phases attributed to their differences in molecular structures (Figure 2).

The selection of suitable column for the separation of LCZ and its 9 impurities was critical. The approach was based on column screening studies where a number of columns with different chemistries were tried. Finally, Kinetex biphenyl column produced the best separation with optimum resolution among the various critical pairs. The organic component of the method was chosen with respect to obtain good resolution and low back pressure. The column temperature was maintained at $45^{\circ} \mathrm{C}$. The retention of the analytes on the stationary phase is dependent on the $\mathrm{pH}$ of the aqueous component. This determines the analytes to be either in ionized or neutral form thereby exerting an effect on their retention behaviour owing to interactions based the polarities of stationary phase and the molecules.

The aim of the present study is to develop a reversedphase high-performance liquid chromatography procedure for the determination of LCZ in the oral solution dosage forms. LCZ is relatively non-polar compound as indicated by partition coefficient $(\log p=4.94$

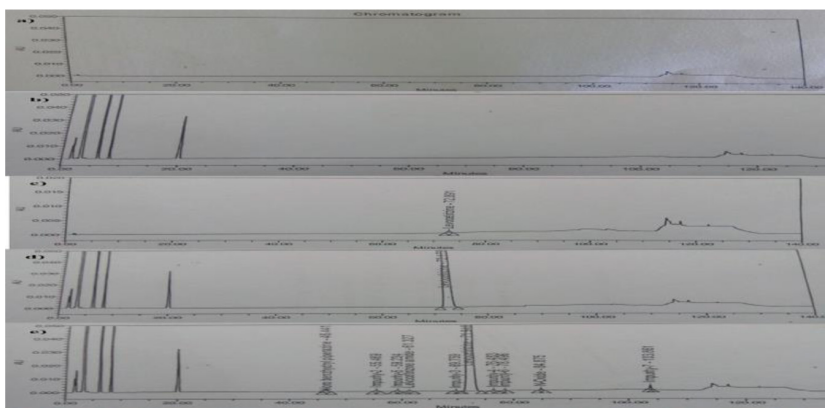

Figure 1: Chromatogram of a) Blank, b) Placebo, c) Standard, d) Unspiked sample, e) Spiked sample.

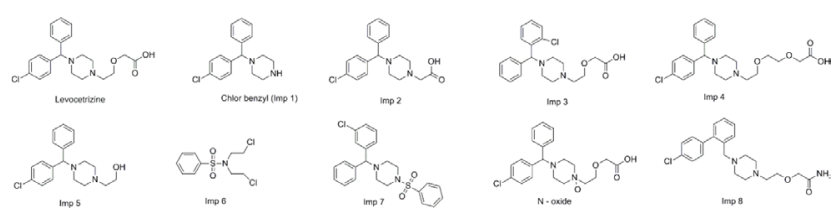

Figure 2: Structures of $L C Z$ and its impurities.

and 6.03) [15], and is well retained on traditional C18 bonded phases. The initial trials were carried out with aqueous buffer solutions of $\mathrm{pH} 3.0,4.0,5.0,5.5$ and 6.0 with organic phase being methanol or acetonitrile. The method was optimized in keeping view of adequate separation of the degradation products from the main peak.

The developed chromatographic method was capable of determining LCZ in its oral solution dosage forms.

\section{Method validation}

The developed method was validated to establish the specificity, precision, linearity, accuracy and robustness according to ICH guidelines. ${ }^{16}$

In the present study where the separation of 9 impurities was carried only two impurities (Imp 1 and $\mathrm{N}$-Oxide impurity) were quantified. Since the other related impurities are process related they need not be quantified and were included to confirm their relative retention time (Shown in Table 1).

\section{Specificity}

The specificity of the method was performed by ensuring the separation of the drug from all the interferences Figure 2 . The specificity of the method was established by evaluating the peak purity of LCZ and all its impurities. The results showed LCZ to be pure and all the degradation products were separated and no other peaks were interfering with it (Table 1).

\section{Limit of detection (LOD) and limit of quantification (LOQ)}

The LOD and LOQ of the developed method were determined by injecting sample solutions of LCZ and 
Table 1: System Suitability Parameters.

\begin{tabular}{|c|c|c|c|c|c|c|}
\hline \multicolumn{3}{|c|}{ Identification and retention time confirmation } & \multicolumn{4}{|c|}{ SST parameters for LCZ } \\
\hline \multirow[b]{2}{*}{ Compound } & Retention Time & \multirow{2}{*}{$\begin{array}{c}\text { Spiked } \\
\text { samples }\end{array}$} & \multirow[b]{2}{*}{ S.No } & \multirow[b]{2}{*}{ Peak area } & \multirow{2}{*}{$\begin{array}{c}\text { Theoretical } \\
\text { plates }\end{array}$} & \multirow{2}{*}{$\begin{array}{l}\text { Tailing } \\
\text { factor }\end{array}$} \\
\hline & $\begin{array}{c}\text { Individual identification } \\
\text { solutions }\end{array}$ & & & & & \\
\hline LCZ & 72.891 & 72.172 & 1 & 30869 & 51985 & 0.98 \\
\hline $\operatorname{Imp} 1$ & 46.449 & 46.441 & 2 & 33087 & 49387 & 0.89 \\
\hline Imp2* & 55.477 & 55.469 & 3 & 32644 & 59171 & 0.92 \\
\hline $\operatorname{Imp5} 5^{*}$ & 59.262 & 59.234 & 4 & 32622 & 51228 & 0.96 \\
\hline $\operatorname{Imp} 8^{*}$ & 61.433 & 61.327 & 5 & 34275 & 44282 & 0.92 \\
\hline $\operatorname{Imp} 3^{*}$ & 69.799 & 69.759 & 6 & 33565 & 48514 & 0.86 \\
\hline Imp4* & 76.435 & 76.483 & Mean & 32844 & 50761 & 0.92 \\
\hline Imp6* & 78.406 & 78.496 & SD & 1150.35 & - & - \\
\hline N-oxide Imp & 84.996 & 84.875 & $\%$ RSD & 3.50 & - & - \\
\hline $\operatorname{Imp} 7^{*}$ & 103.903 & 103.861 & & & & \\
\hline
\end{tabular}

*As these are process related impurities, given for relative retention time confirmation not for quantification.

\begin{tabular}{|c|c|c|c|c|c|}
\hline \multicolumn{6}{|c|}{ LCZ } \\
\hline Level & $\begin{array}{l}\text { Concentration } \\
\text { (in ppm) }\end{array}$ & Mean Peak Area & $\%$ RSD & \multicolumn{2}{|c|}{ Statistical Analysis } \\
\hline LOQ & 0.048 & 3418 & 6.35 & Correlation coefficient $(r)$ & 0.99926 \\
\hline Level-1 & 0.250 & 15720 & - & r 2 & 0.99853 \\
\hline Level-2 & 0.376 & 24987 & - & Slope & 64730.04 \\
\hline Level-3 & 0.501 & 33570 & - & $y$-intercept & 301.82 \\
\hline Level-4 & 0.626 & 41118 & - & $\% y$-intercept & 0.90 \\
\hline Level-5 & 0.751 & 48189 & 2.20 & - & - \\
\hline \multicolumn{6}{|c|}{ Imp 1} \\
\hline Level & $\begin{array}{c}\text { Concentration } \\
\text { (in ppm) }\end{array}$ & Mean Peak Area & $\%$ RSD & \multicolumn{2}{|c|}{ Statistical Analysis } \\
\hline LOQ & 0.041 & 4380 & 6.77 & Correlation coefficient $(r)$ & 0.99984 \\
\hline Level-1 & 0.249 & 28820 & - & r 2 & 0.99968 \\
\hline Level-2 & 0.374 & 41353 & - & Slope & 112354.14 \\
\hline Level-3 & 0.499 & 56366 & - & $y$-intercept & 33.77 \\
\hline Level-4 & 0.623 & 69834 & - & $\% y$-intercept & 0.06 \\
\hline Level-5 & 0.748 & 84155 & 1.36 & - & - \\
\hline \multicolumn{6}{|c|}{ N-Oxide Imp } \\
\hline Level & $\begin{array}{l}\text { Concentration } \\
\text { (in ppm) }\end{array}$ & Mean Peak Area & $\%$ RSD & \multicolumn{2}{|c|}{ Statistical Analysis } \\
\hline LOQ & 0.050 & 3235 & 2.58 & Correlation coefficient $(r)$ & 0.99934 \\
\hline Level-1 & 0.250 & 14286 & - & r2 & 0.99868 \\
\hline Level-2 & 0.375 & 22602 & - & Slope & 61961.38 \\
\hline Level-3 & 0.500 & 29795 & - & $y$-intercept & -570.09 \\
\hline Level-4 & 0.625 & 38155 & - & \%y-intercept & -1.91 \\
\hline Level-5 & 0.750 & 46508 & 2.17 & - & - \\
\hline
\end{tabular}

all its impurities individually by progressively decreasing the concentration of the analyte (Table 3).

\section{Linearity}

The linearity of the method was checked by injecting six concentration levels of LCZ, Imp 1 and N-Oxide impurity ranging from LOQ to $150 \%$ of specification level. Each solution was injected in triplicate and the mean was taken for calculation. Calibration equation was obtained from linear regression analysis and the correlation coefficient was found to be 0.99961 which shows that the method is linear. The regression equation for the 
calibration curve was found to be $\mathrm{y}=32224.51 \mathrm{x}+$ 46741 (Table 2).

\section{Accuracy}

The accuracy of the method was evaluated in triplicate at three concentration levels, i.e. 50\%,100\% and $150 \%$ levels by spiking the drug LCZ and all the impurities in tablet placebo. The percentage of recovery of the drug was calculated at each level. The percentage recovery of the LCZ and its impurities ranged from 98.9\% to $100.7 \%$ indicating the accuracy of the method (Table 5).

\section{Precision}

The precision studies are performed to evaluate the repeatability of the method. The repeatability of the proposed method was demonstrated by analyzing six separate samples solutions of LCZ spiked with its 8 impurities ( $0.1 \%$ level with respect to LCZ concentration). The $\%$ RSD for the peak areas of different injections were calculated and were found to be less than 2 showing the method to be highly precise. The results are shown in Table 4.

\section{Robustness}

The experimental conditions were deliberately changed in order to determine the robustness of the developed method and percentage assay and tailing factor of the main peak was evaluated. Observation of the results for deliberately changed chromatographic conditions (flow rate, and column temperature) revealed percentage assay and also the tailing factor were within the limits, illustrating the robustness of the method.

\begin{tabular}{|c|c|c|c|}
\hline \multicolumn{4}{|c|}{ Table 3: LOD and LOQ data of LCZ. } \\
\hline \multirow{3}{*}{ Component } & Concentration (in \%) & S/N ratio \\
\cline { 2 - 4 } & Imp 1 & $\mathbf{0 . 0 1 3}$ & $\mathbf{5}$ \\
\hline \multirow{2}{*}{ LOD } & LCZ & 0.016 & 4 \\
\cline { 2 - 4 } & N-Oxide Imp & 0.017 & 5 \\
\hline \multirow{3}{*}{ LOQ } & Imp 1 & 0.041 & 13 \\
\cline { 2 - 4 } & LCZ & 0.048 & 11 \\
\cline { 2 - 4 } & N-Oxide Imp & 0.050 & 15 \\
\hline
\end{tabular}

\begin{tabular}{|c|c|c|c|}
\hline \multirow{2}{*}{ Validation Parameter } & \multicolumn{3}{|c|}{ Table 4: Precision data. } \\
\hline \multirow{3}{*}{ System Precision } & Minimum theoretical plates & 44481 & 37116 \\
\cline { 2 - 4 } & Maximum tailing factor & 0.99 & 1.02 \\
\cline { 2 - 4 } & \%RSD & 3.04 & 3.98 \\
\hline \multirow{4}{*}{ Method Precision } & Impurities & Unspiked Samples & Spiked samples \\
\cline { 2 - 4 } & Imp 1 & NA & 2.12 \\
\cline { 2 - 4 } & Maximum individual unspecified impurity & NA & 3.43 \\
\cline { 2 - 4 } & Total Impurities & NA & NA \\
\hline \multirow{3}{*}{ Intermediate Precision } & Imp 1 & 1.20 & 2.67 \\
\cline { 2 - 4 } & Maximum individual unspecified impurity & 1.65 & 3.07 \\
\cline { 2 - 4 } & Total Impurities & NA & 2.82 \\
\cline { 2 - 4 } & & 0.56 & NA \\
\hline
\end{tabular}

\begin{tabular}{|c|c|c|c|c|c|}
\hline \multirow{5}{*}{ Accuracy } & \multirow{2}{*}{ Component } & \multicolumn{4}{|c|}{$\%$ Recovery } \\
\hline & & LOQ & $50 \%$ level & $100 \%$ level & $150 \%$ level \\
\hline & LCZ & 103.1 & 100.0 & 101.0 & 101.9 \\
\hline & $\operatorname{Imp} 1$ & 101.9 & 102.1 & 102.1 & 105.7 \\
\hline & N-Oxide Imp & 105.5 & 96.5 & 103.1 & 106.6 \\
\hline
\end{tabular}




\section{CONCLUSION}

A simple, precise and accurate HPLC method was developed to separate and quantify LCZ and its related impurities. The developed method was validated according to $\mathrm{ICH}$ guidelines and demonstrated to be specific, linear, precise, accurate and robust. The specificity results indicated the stability indicating power of the proposed chromatographic method. The method can be successfully employed in regular analysis and quality control laboratories.

\section{ACKNOWLEDGEMENT}

The authors wish to thank the management of CJ Pharma Research India Pvt. Ltd. and BIT Mesra (Ranchi) for providing the facilities to carry out the research work.

\section{CONFLICT OF INTEREST}

The authors declare no conflict of interest.

\section{ABBREVIATIONS}

LCZ: Levocetrizine dihydrochloride; HPLC: High Performance Liquid Chromatography; ICH: International Conference on Harmonization; \%RSD: Percent relative standard deviation.

\section{REFERENCES}

1. Simons FE, Advances in H1-Antihistamines, $\mathrm{N}$ Engl $\mathrm{J}$ Med. 2004;351(21):2203-17.

2. Kapp A, Pichler WJ. Levocetirizine is an effective treatment in patients suffering from chronic idiopathic urticaria: A randomized, double blind, placebo controlled, parallel, multicenter study, International journal of dermatology. 2006;45(4):469-74.

3. Garlapati VK, Roy L. Utilization of Response Surface Methodology for Modeling and Optimization of Tablet Compression, J Young Pharm. 2017;9(3):417-21.

4. Prabhu P, Malli R, Koland M, Vijaynarayana K, D'Souza U, Harish NM, et al. N Charyulu, Formulation and evaluation of fast dissolving films of levocitirizine

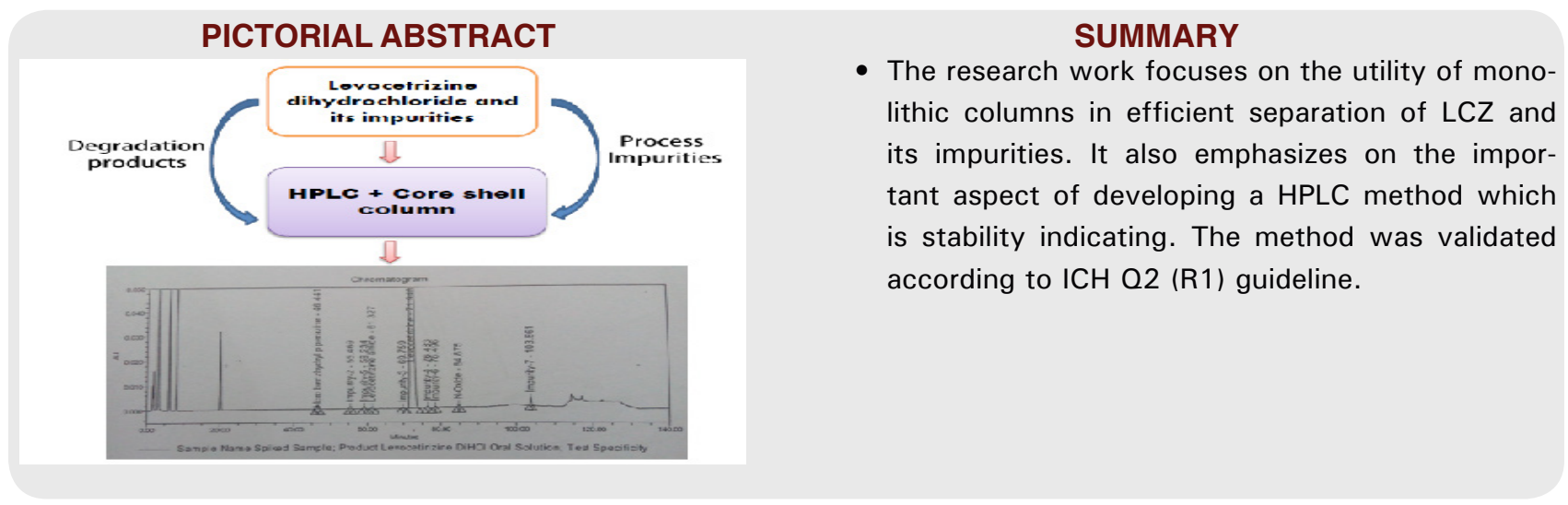

di hydrochloride, International Journal of Pharmaceutical Investigation. 2011;1(2):99-104.

5. Priya VR, Rani SS, Pavan RA, Naresh G, Ahad HA. Novel Approach in Designing Mouth Dissolving Tablets of Cetirizine Hydrochloride, Indian Journal of Pharmaceutical Education and Research. 2012;46(3):253-8.

6. Das S, Mondal S, Dey JK, Bandyopadhyay S, Saha I, Tripathi SK. A case of montelukast induced hypercholesterolemia, severe hypertriglyceridemia and pancreatitis, Journal of Young Pharmacists. 2013;5(2):64-6.

7. Guptha SD, Prabhakar SM, Sacchidanand S. Fixed drug eruption due to levocetirizine, Indian Journal of Dermatology, Venereology, and Leprology. 2005;71(5):361.

8. Görög S. The importance and the challenges of impurity profiling in modern pharmaceutical analysis, TrAC Trends in Analytical Chemistry. 2006;25:755-7.

9. Guiochon $\mathrm{G}$. Monolithic columns in high-performance liquid chromatography, Journal of Chromatography A. 2007;1168(1-2):101-68.

10. Ikegami T, Tanaka N. Monolithic columns for high-efficiency HPLC separations, Current opinion in chemical biology. 2004;8(5):527-33.

11. Quigley CL, Marlin ND, Melin V, Manz A, Smith NW. Advances in capillary electrochromatography and micro high performance liquid chromatography monolithic columns for separation science, Electrophoresis. 2003;24(6):917-44.

12. Tanaka N, Kobayashi H, Nakanishi K, Minakuchi H, Ishizuka N. Peer reviewed: monolithic LC columns, Analytical chemistry. 2001;73:420A-9.

13. Unger KK, Skudas R, Schulte MM. Particle packed columns and monolithic columns in high-performance liquid chromatography-comparison and critical

14. Kele M, Guiochon G. Repeatability and reproducibility of retention data and band profiles on six batches of monolithic columns, Journal of Chromatography A. 2002;960(1-2):19-49.

15. Šatınský D, Solich P, Chocholouš P, Karlíček R. Monolithic columns-a new concept of separation in the sequential injection technique, Analytica Chimica Acta. 2003;499(1-2):205-14.

16. Lixing Z, Jianhe S, Xiaofeng Z, Zhihong C. Determination of Levocetirizine Hydrochloride and Its Related Substances in Levocetirizine Hydrochloride Orally Disintegrating Tablets by HPLC, China Pharmaceuticals. 2008;12:37.

17. Somkuwar S, Pathak A. Simultaneous estimation of levocetirizine dihydrochloride and montelukast sodium by RP-HPLC Method, Pharmacia. 2012;1:90-4.

18. Gunjal RP, Raju G, Babu AR, Mallikarjun N, Shastri N, Srinivas R. Studies on stress degradation behavior of levocetirizine and development of a validated specific stability-indicating method Journal of Liquid Chromatography and Related Technologies. 2011;34(12):955-65.

19. Arayne MS, Sultana N, Zeeshan MA, Siddiqui FA. Simultaneous determination of gliquidone, fexofenadine, buclizine, and levocetirizine in dosage formulation and human serum by RP-HPLC Journal of chromatographic science. 2010;48(5):382-5.

20. Validation of analytical procedures: Text and methodology Q2 (R1). ICH harmonised tripartite guideline. International conference on harmonisation of technical requirements for registration of pharmaceuticals for human use (ICH). 2005. appraisal, Journal of Chromatography A. 2008;1184(1-2):393-415. 


\section{About Authors}

Venkatakrishna is a PhD Scholar in Birla Institute of Technology (BIT), Mesra, Jharkhand, India. Areas of interest: Analytical method development and validation, Impurity profiling, structural characterization of impurities using LC-MS and NMR.

Dr Barij Nayan Sinha is a Professor in Pharmaceutical Sciences and Technology of Birla Institute of Technology (BIT), Mesra, Jharkhand, India. Areas of interest: Analytical method development and validation, Drug Discovery Approaches with regard to Synthetic and Natural Leads using Modern Analytical Techniques and Software's.

Dr Han Jeongseok is a Principal Senior Scientist at Pharma Development Center in CJ Pharma Research India Pvt. Limited. Areas of interest: Analytical method development and validation

Cite this article: Akula V, Sinha BN, Seok HJ. Stability Indicating Hplc Method using Core Shell Stationary Phase for the Determination of Related Substances in Levocetirizine Dihydrochloride Oral Solution. Indian J of Pharmaceutical Education and Research. 2018;52(4):684-90. 